Article

\title{
MBES-CARIS Data Validation for Bathymetric Mapping of Shallow Water in the Kingdom of Bahrain on the Arabian Gulf
}

\author{
Abderrazak Bannari * and Ghadeer Kadhem \\ Department of Geoinformatics, College of Graduate Studies, Arabian Gulf University, P.O. Box 26671, \\ Manama 329, Bahrain; ghadeermrk@agu.edu.bh \\ * Correspondence: abannari@agu.edu.bh; Tel.: +973-1723-9545; Fax: +973-1723-9552
}

Academic Editors: Deepak R. Mishra and Prasad S. Thenkabail

Received: 19 February 2017; Accepted: 16 April 2017; Published: 19 April 2017

\begin{abstract}
Sound navigating and ranging (SONAR) detection systems can provide valuable information for navigation and security, especially in shallow coastal areas. The last few years have seen an important increase in the volume of bathymetric data produced by Multi-Beam Echo-sounder Systems (MBES). Recently, the General Bathymetric Chart of the Oceans (GEBCO) released these MBES dataset preprocessed and processed with Computer Aided Resource Information System (CARIS) for public domain use. For the first time, this research focuses on the validation of these released MBES-CARIS dataset performance and robustness for bathymetric mapping of shallow water at the regional scale in the Kingdom of Bahrain (Arabian Gulf). The data were imported, converted and processed in a GIS environment. Only area that covers the Bahrain national water boundary was extracted, avoiding the land surfaces. As the released dataset were stored in a node-grid points uniformly spaced with approximately $923 \mathrm{~m}$ and $834 \mathrm{~m}$ in north and west directions, respectively, simple kriging was used for densification and bathymetric continuous surface map derivation with a 30 by $30 \mathrm{~m}$ pixel size. In addition to dataset cross-validation, 1200 bathymetric points representing different water depths between 0 and $-30 \mathrm{~m}$ were selected randomly and extracted from a medium scale $(1: 100,000)$ nautical map, and they were used for validation purposes. The cross-validation results showed that the modeled semi-variogram was adjusted appropriately assuring satisfactory results. Moreover, the validation results by reference to the nautical map showed that when we consider the total validation points with different water depths, linear statistical regression analysis at a $95 \%$ confidence level $(p<0.05)$ provide a good coefficient of correlation $\left(R^{2}=0.95\right)$, a good index of agreement $(\mathrm{D}=0.82)$, and a root mean square error (RMSE) of $1.34 \mathrm{~m}$. However, when we consider only the validation points ( 800) with depth lower than $-10 \mathrm{~m}$, both $\mathrm{R}^{2}$ and $\mathrm{D}$ decreased to 0.79 and 0.52 , respectively, while the RMSE increased to $1.92 \mathrm{~m}$. Otherwise, when we consider exclusively shallow water points $(\sim 400)$ with a depth higher than $-10 \mathrm{~m}$, the results showed a very significant $\mathrm{R}^{2}$ (0.97), a good D (0.84) and a low RMSE (0.51 m). Certainly, the released MBES-CARIS data are more appropriate for shallow water bathymetric mapping. However, for the relatively deeper areas the obtained results are relatively less accurate because probably the MBSE did not cover the bottom in several deeper pockmarks as the rapid change in depth. Possibly the steep slopes and the rough seafloor affect the integrity of the acquired raw data. Moreover, the interpolation of the missed areas' values between MBSE acquisition data points may not reflect the true depths of these areas. It is possible also that the nautical map used for validation was not established with a good accuracy in the deeper regions.
\end{abstract}

Keywords: bathymetry; shallow water; SONAR; MBES; CARIS; validation; nautical map 


\section{Introduction}

The marine environment is divided into open ocean and coast, which includes estuaries, coral reefs and shelf systems. It is a critical habitat for submerged aquatic vegetation, grass and algae [1], which serve as important indicators for water quality and a highly effective sink for atmospheric carbon dioxide [2]. In addition to valuable ecosystem services, shallow coastal areas present unique challenges for navigation and security. They play a fundamental role in the sustainability of global ecosystem biodiversity and mitigate the impact of storms, floods and sea level rise damage for people living in coastal regions [3]. Consequently, bathymetry information must be updated frequently for many applications, especially oceanographic research, marine ecosystems, environmental disaster management and planning near-shore structure activities. These include sensitive engineering projects such as oil exploration, pipeline laying, maritime transportation and port management, fishing and aquaculture breeding, etc. [4]. Moreover, knowledge of water depth also allows an estimation of the sediment budget to maintain the manmade channel depth for smooth navigation [5], especially in the Kingdom of Bahrain where many artificial small islands are under construction.

Traditionally, water depth was often mapped from irregular surveys of limited sampling points based on irregularly distributed point observations collected through underwater divers using rope or cable [6]. Then, bathymetric maps were generated using interpolation techniques. This traditional method is laborious, inefficient, expensive and time-consuming. Currently, several new methods are available for bathymetric information retrieval, such as optical remote sensing (multispectral and hyperspectral) [7-9], laser systems such as Lidar [10] and active sound navigation and ranging (SONAR) detection systems. For instance, the multi-beam echo-sounder systems (MBES) employ acoustic detection techniques to collect detailed data in a cross-section of the sea bottom. MBES collects bathymetric soundings in a swath electronically forming a series of transmitted and received beams in the transducer hardware that measure the depth to the seafloor in discrete angular increments or sectors across the swath [11]. It sweeps a large swath of the seafloor by emitting a fan of narrow sound beams and it is currently considered to be the most efficient and accurate system available to collect bathymetric and backscatter data [12-14]. The inherent bathymetric and backscatter data acquired by MBES enables marine scientists to generate accurate bathymetric information with a spatial resolution closely matching that of terrestrial mapping [15]. A Global Position System (GPS) signal is required to assign positions to the MBES in the ship as well as an Inertial Navigation System (INS) to follow the ship attitude (roll, pitch, way, and azimuth) and speed variation measurements. Cleveland [16] provides more information and details about MBES data collection procedure and transmission mode.

According to Calder and Mayer [17] MBES is the best way to accurately determine the bathymetry of large regions of the seabed. Their users include hydrographers, navigators, engineers, marine geologists, military planners, maritime explorers, archaeologists, fisheries biologists, geomorphologists and ecosystem modelers [18]. It has significant advantages in delineating the morphology of the seabed, but comes with the disadvantage of having to handle and process a much greater volume of data. The raw bathymetric data collected by MBES are preprocessed and processed using Computer Aided Resource Information System (CARIS) and Hydrographic Information Processing System (HIPS) software. The concept of CARIS was born and developed by professor Salem Masry in 1979 at the University of New Brunswick (NB) in Canada. While it is still headquartered in NB, CARIS now operates offices in the United States, Australia, the UK, and the Netherlands, and offer services to more than 90 countries. Currently, three different processes are available in CARIS-HIPS software to generate depth estimations: (1) swath angle, (2) uncertainty and data CUBE (Combined Uncertainty and Bathymetry Estimator) algorithm for bathymetric data analysis, and (3) filtering and cleaning $[19,20]$. The results are presented in a CARIS BASE (Bathymetry with Associated Statistical Error) surface of depth calculated from MBES data without validation or any prior knowledge of the truth of the water depths, but it gives an uncertainty for each estimated node. According to CARIS [20], the MBES-CARIS software allows the implementation of surfaces with statistical weight 
and meets hydrographic standards. Currently, it is the software that is used by the National Oceanic and Atmospheric Administration (NOAA) hydrographers to process bathymetry data [21].

During the last decade, most of the CARIS-HIPS research focused on computer-assisted methods of estimating plausible depths from MBES raw data. Unfortunately, without end-user interaction and the algorithm results-performance it is always assessed and validated only on a small subset of data, which therefore requires validation over a large territory. Moreover, the influence of the data preprocessing and processing methods on the depth and uncertainty is still not well studied [22]. With algorithms that are more complex and based on several assumptions, it is less obvious to predict what the effects are likely to be, but the fact of a modeling uncertainty remains on the bathymetric depths estimation. However, the uncertainty associated with a depth estimate was modeled and quantified by several scientists using different methods [18,22-27]. According to Smith et al. [28], for each node in the grid for a given working site an uncertainty value is modeled and computed, and it should be around or less than $0.30 \mathrm{~m}$. Based on physical simulations, residual uncertainties of any MBES can be expected to vary from $0.10 \mathrm{~m}$ to $0.30 \mathrm{~m}$ and increase with depth [29]. In the Timor Sea (Australia), using the Kongsberg EM3002D (300 kHz) sonar system, Lucieer et al. [18] showed that the depth uncertainty ranged from $0.31 \mathrm{~m}$ to $0.60 \mathrm{~m}$ and gradually increased from the nadir to outer beams $(1.50 \mathrm{~m})$. Near Petit Bois Island, Gulf Islands National Seashore (Mississippi, USA), bathymetric data were collected by USGS using SONAR and were then processed using CARIS-HIPS associated with CUBE to create a depth map with a $50 \mathrm{~m}$ pixel size [30]. The cross-validation of this map, using measured and predicted points, showed that the errors vary between 0.18 and $0.90 \mathrm{~m}$. As well, a German project in the Northern Weddell Sea estimated the depths uncertainty in shallow areas to be between 0.50 and $1.00 \mathrm{~m}$ [31]. Another pilot project was initiated by the Canadian Hydrographic Service (CHS) to evaluate the solution provided by the CARIS Bathymetry database in the Saint-Lawrence River (Quebec Region) as a part of a larger initiative to integrate database-driven technologies for bathymetric mapping [32,33]. The results of this project showed that the benefits of this new approach are providing simpler and faster access to bathymetry data while maintaining the expected standard for hydrographic products. According to CHS [34], for the best extract of bathymetric information, the uncertainty must be less than $0.50 \mathrm{~m}$ for the shallow water (depth $<25 \mathrm{~m}$ ). However, in the Chilean Patagonian waters the extreme seafloor morphology decreased the CUBE efficiency and significantly increased the uncertainty [35]. Considering the same coastal area near Victoria (Australia), repeated MBES surveys for seafloor altitude change under sedimentation processes showed that the uncertainty in these MBES datasets affects the estimation of the altitude change considerably [36]. In the context of providing accurate mariners nautical chart products and information to navigate safely, NOAA compared several MBES datasets for estimating failed-wreck depths. This study showed significant depth differences of $5.45 \mathrm{~m}$ and $5.62 \mathrm{~m}$ [21] that exceeded the International Hydrographic Organization (IHO) standard [37]. According to Wyllie et al. [21], a fishery multi-beam water column sonar operating in bathymetry mode can explain these substantial differences and a mast that is smaller than the beam footprint and depths of $110 \mathrm{~m}$ causing the majority of main lobe energy to miss the mast and detect the wreck structure below it.

To improve bathymetric data accessibility via the web, CARIS developed a new storage technology that will allow its users to store, process, and visualize very large volumes of data in a unique approach named CSAR, CARIS Spatial Archive [38]. Moreover, the generated bathymetric attributed node-grid points files (X, Y, and depth) from MBES were made available for the users around the world in the General Bathymetric Chart of the Oceans (GEBCO) digital atlas database [39]. In this research, we validated for the first time the MBES-CARIS depth-surface data performance and robustness for bathymetric mapping of shallow water at the regional scale in the Kingdom of Bahrain (Arabian Gulf). The free-released data were imported, converted and processed in a GIS environment [40] using simple kriging. The cross-validation procedure was considered for the data quality assessment and the semi-variogram adjustment and analysis. For validation purposes, 1200 bathymetric points representing different water depths $(-0.5 \mathrm{~m} \leq$ depth $\leq-30 \mathrm{~m})$ across the Bahrain national water 
boundary were selected randomly and extracted from a medium scale $(1: 100,000)$ nautical map established by the British navy (observed values), and they were fitted with their homologous generated points from MBES-CARIS data (predicted values) using linear regression $(p<0.05)$.

\section{Material and Methods}

\subsection{Study Site}

The area under investigation in this research is the water boundary of the Kingdom of Bahrain which is a group of islands located in the Arabian Gulf (Figure 1), east of Saudi Arabia and west of Qatar $\left(26^{\circ} 00^{\prime} \mathrm{N}, 50^{\circ} 33^{\prime} \mathrm{E}\right)$. The archipelago comprises 33 islands, with a total land area of about $765.30 \mathrm{~km}^{2}$ [41]. The marine and coastal ecosystems in Bahrain are very important natural resources, which play an important role in the development of the country's economy. Approximately $126 \mathrm{~km}$ of coastlines and $8000 \mathrm{~km}^{2}$ of marine area have been supporting Bahraini people with fish and pearls for hundreds of years [42]. Along the southwest coast of Bahrain, the continental plateau extends for kilometers with a depth of less than one or two meters [43]. In addition to tides phenomena, the atmospheric conditions play an important role in the control of water levels variability [44]. The northwest wind can lower the water level close to the north of the Bahrain coasts, while the southeast wind can raise the water level. When both wind directions are blowing with a cold front crossing the region, there is probably, an important increase in the water level close to the northern Bahrain coast zones [42]. Shallow coastal areas in Bahrain rarely exceed a depth of $-25 \mathrm{~m}$. The main island of Bahrain is surrounded by areas named "Fashts" where depths do not exceed $-10 \mathrm{~m}$. These areas generally support variety of species of seagrass, algae, coral, and fishes [45]. Moreover, they play an important role in the hydrodynamic regime of the area north of Bahrain, which supports diverse biological ecosystems [46]. Obviously, it is necessary to monitor the coastal environment development, to apply coastal resources management policy accurately and to update the marine bathymetry map.

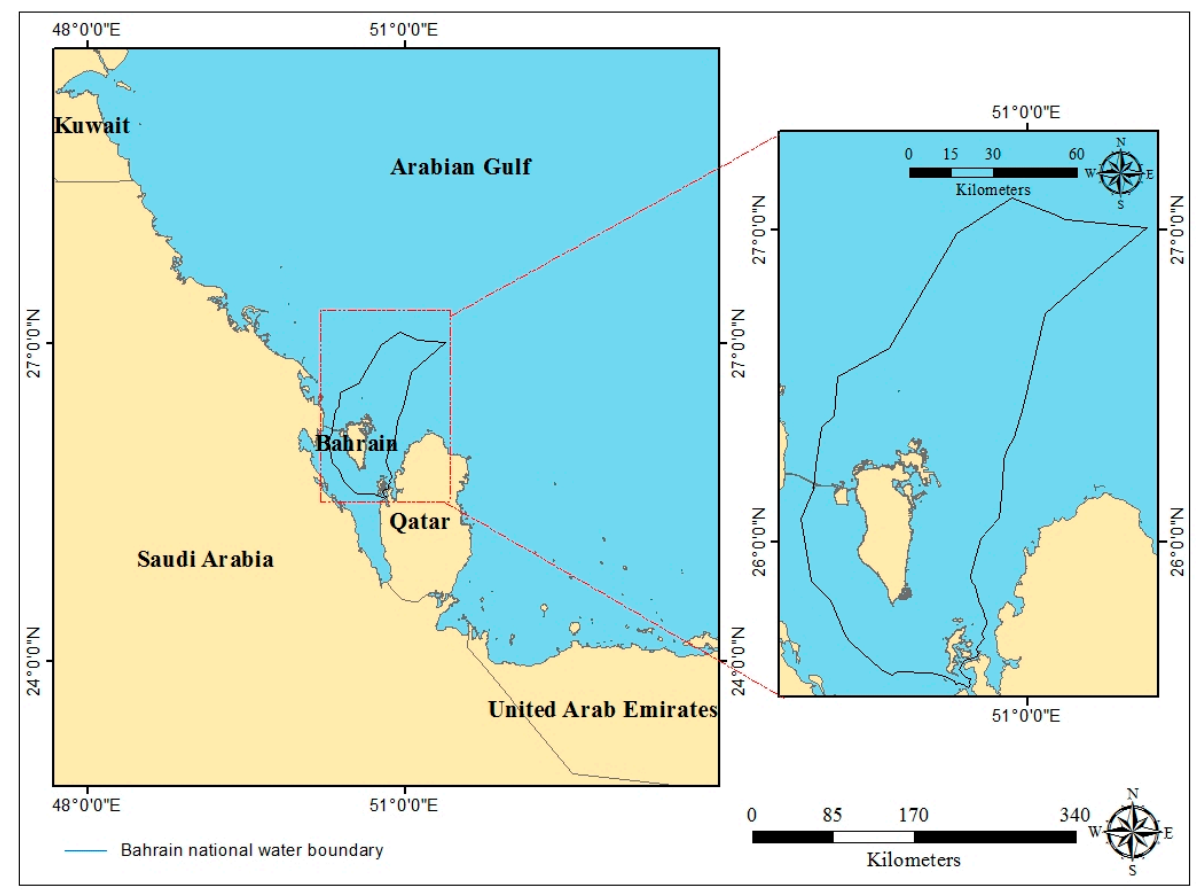

Figure 1. Study area, Kingdom of Bahrain national water boundary.

\subsection{MBES-CARIS Data Processing}

The data used in this research are courtesy of CARIS EMEA Marketing and Sales Services (The Netherlands), and they are also available in the GEBCO database [39]. They were collected by 
MBES, preprocessed and processed using CARIS-HIPS software [20]. These steps were performed considering the corrections of tide, vessel attitude (pitch, roll and heave), sound velocity profiles (variations in the speed of sound through the water column during the data acquisition), filtering and cleaning to eliminate artefacts and noise in the data. The bathymetry nodes-grid was then generated from the CUBE algorithm, which also generated the uncertainty layer representing a priori uncertainty of the depth at each node of the grid points. This uncertainty varied from $0.30 \mathrm{~m}$ to $0.90 \mathrm{~m}$ and gradually increased from nadir to beams extremities. The generated node-grid point's data were handled and evaluated in an ArcGIS environment following four major steps (Figure 2). They were converted from ASCII file format (X, Y, and depth) to point's shapefile. Then, the Bahrain national water boundary shapefile was used to extract the area covering only the water boundary and avoiding the land surfaces (Figure 3). The depth values in all considered node points were multiplied by " -1 " to get the negative values for bathymetric altitudes with reference to mean sea level (MSL). As the dataset were stored in regular grid points (Figure 4) uniformly spaced with approximately $923 \mathrm{~m}$ and $834 \mathrm{~m}$ in north and west directions, respectively, interpolation method was requested for densification to cover all areas without depth information and to generate a new raster bathymetric grid surface.

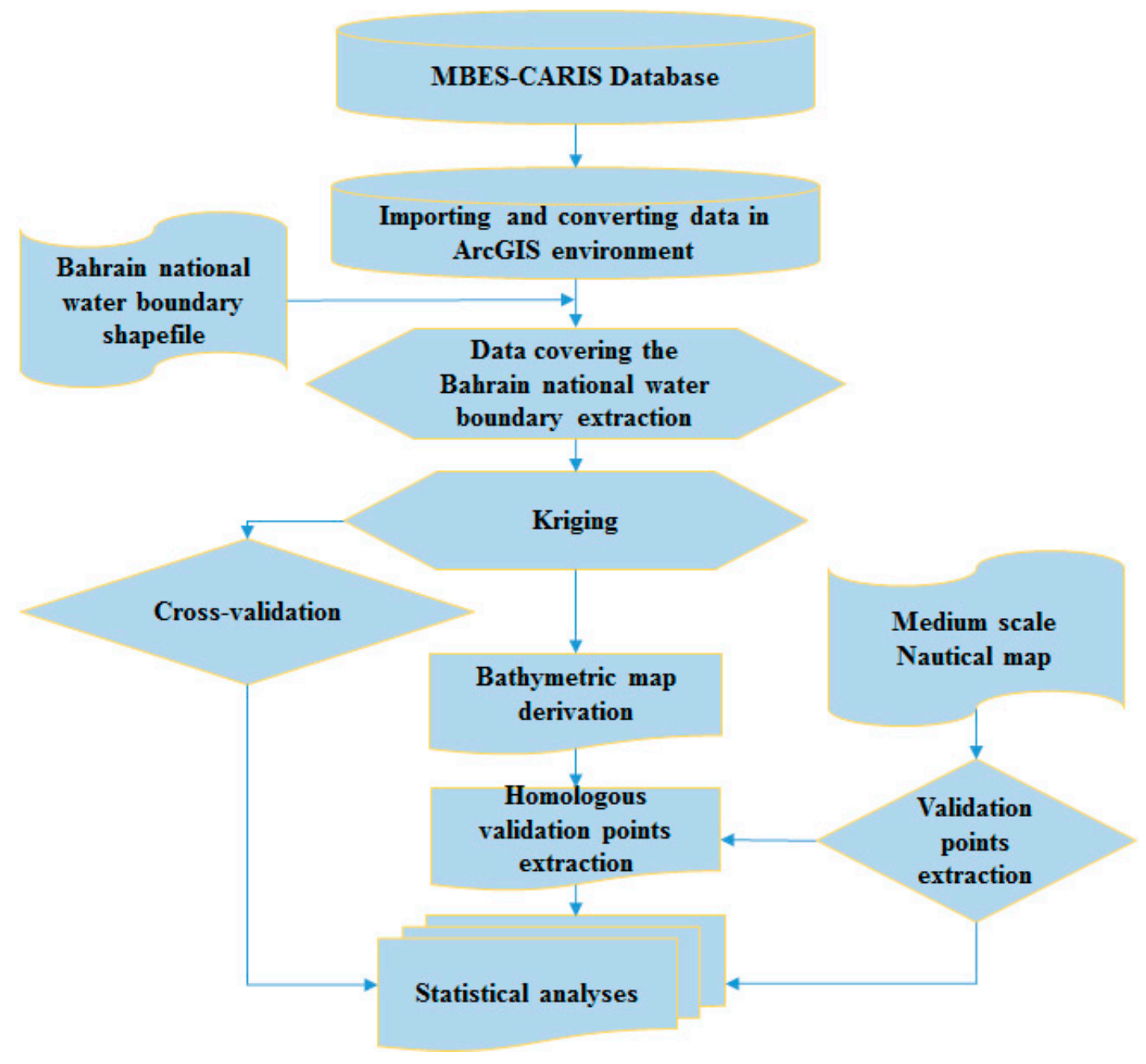

Figure 2. Methodology flowchart. 


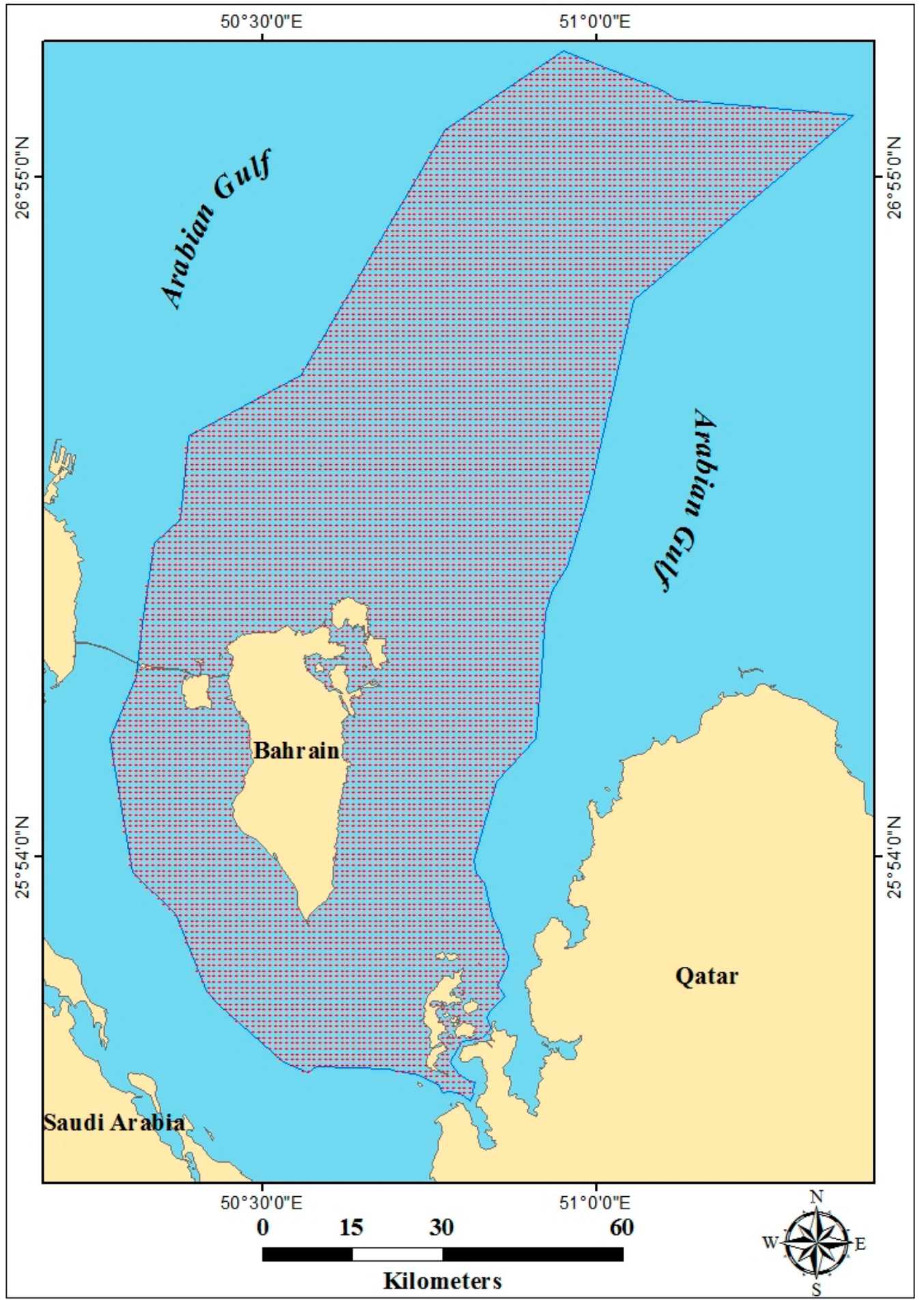

Figure 3. Kingdom of Bahrain national water boundary shapefile with MBES collected data. 


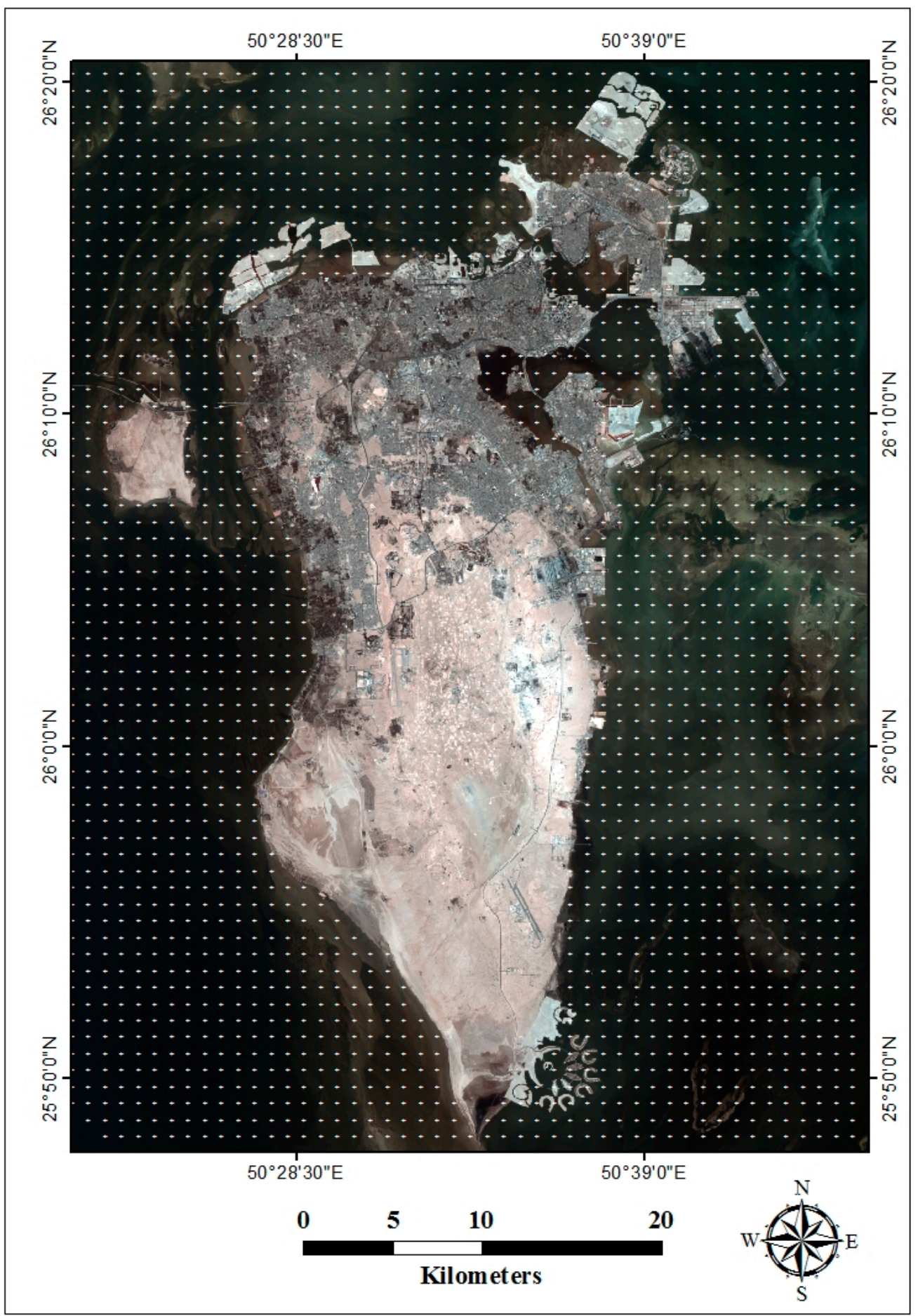

Figure 4. Zoom on the node points near to Bahrain mean Island that are superimposed on Landsat-8 image.

Selection of an appropriate spatial interpolation method for bathymetric mapping is not an easy task, because the performance of spatial interpolators depends on many factors [47], and it seems that there is no simple answer regarding the choice of an appropriate spatial interpolator because a method is "best" only for specific situations [48,49]. Several interpolation methods exist in ArcGIS [40] and other mapping software's and the best and most appropriate seabed-topography interpolation method must reproduce the marine terrain shape as closely as possible [50]. Zimmerman et al. [51] and 
Arun [52] revealed that the kriging approach adjusted itself to the spatial data structure and provided better estimations of the altitude than other interpolation methods. Curtarelli et al. [53] assessed the performance of different interpolation algorithms (deterministic and stochastic) for bathymetric mapping through cross-validation and Monte-Carlo simulation. They showed that all interpolation methods were able to map important bathymetric features, but the best performance was yielded by the ordinary kriging method ensuring the highest correlation (99.7\%) and the lowest root mean square error (RMSE of $0.92 \mathrm{~m}$ ) when compared to other interpolation algorithms. Šiljeg et al. [54] compared the efficiency of 14 different interpolation methods for a lake bathymetric survey and they discovered that the most appropriate method was ordinary kriging. For Australian marine environmental applications, $\mathrm{Li}$ and Heap [47] compared more than 20 interpolation techniques and they considered ordinary kriging to be the most appropriate method because of its precision and the smoothness of its interpolated surface. However, Bottelier et al. [55] and Kielland et al. [56] preferred simple kriging to simultaneously interpolate a bathymetric surface and compute the uncertainty associated with it. In this study, ordinary and simple kriging were tested, and based on cross-validation between the measured (observation) and the estimated depths values (prediction) simple kriging (SK) was chosen because it provides the best prediction results. For subsequent analysis, the final bathymetric surface was generated with a $30 \mathrm{~m}$ by $30 \mathrm{~m}$ pixel size, projected in the UTM system (zone 39), and considering the WGS84 geodetic reference.

\subsection{Cross-Validation and Validation Statistical Analyses}

Spatial prediction using kriging involves the inversion of a covariance matrix. When the number of locations is very large as in this study (i.e., 10,227 node-grid points distributed uniformly), inversion of the covariance matrix may not be practical. Therefore, efficient cross-validation is very helpful for spatial prediction with large data to assess how well an approximation works [57]. It consists of leaving out one data point at a time, and determining how well this point can be predicted from the neighboring points. In other words, it assesses the anomaly of the used data independently. In this cross-validation procedure, three errors were measured and analyzed using geostatistical modules in ArcGIS [40]: the Mean Standardized Error (MSE), the RMSE and the Root Mean Square Standardized Error (RMSSE). Based on these error values analyses, the semi-variogram was adjusted several times until the best fit of the model was achieved.

In the context of the validation by reference to the truth of the water depths (nautical map, Figure 5), statistical analyses were computed with "Statistica" software. For this step, various statistics tests were computed between the truth which consists of observed values extracted from the nautical map depth established by the British navy in 1997 and the modeled (predicted) values derived from the bathymetric map generated by MBES-CARIS using simple kriging. The relationships between the observed and predicted values were analyzed using a linear regression model $(p<0.05)$, and the correlation coefficient $\left(\mathrm{R}^{2}\right)$ of this regression was used to evaluate the strength of this linear relationship. For the validation process, 1200 points were extracted from the nautical map and their homologous from the MBES-CARIS derived map were compared using the 1:1 line (first besectrix). Ideally, the observed and predicted values should have a correspondence of 1:1. An index of agreement (D) reflects the degree to which the observed value is accurately estimated by the predicted value. The index of agreement was calculated as follows [58]:

$$
D=1-\left[\frac{\sum_{i=1}^{n}\left(P_{i}-O_{i}\right)^{2}}{\sum_{i=1}^{n}\left(\left|P_{i}^{\prime}\right|+\left|O_{i}^{\prime}\right|\right)^{2}}\right]
$$

where $P_{i}$ is the predicted value at sample $i, O_{i}$ is the observed value at sample $i, P_{i}{ }^{\prime}$ is the difference between $P_{i}$ and the average of the predicted values, and $O_{i}{ }^{\prime}$ is the difference between $O_{i}$ and the average of the observed values and $n$ is the number of values. This index provides a measure of the degree to which a model's predictions are error free. The index ranges between 0 and 1 , with 
1 indicating a perfect match between observed and predicted values. The RMSE was used as an additional measure to the overall error to supplement the index of correlation described above. This error also quantifies the 1:1 relationship between observed and predicted values. It was calculated as follows [58]:

$$
\text { RMSE }=\sqrt{\frac{\sum_{i=1}^{n}\left(P_{i}-O_{i}\right)^{2}}{n}}
$$

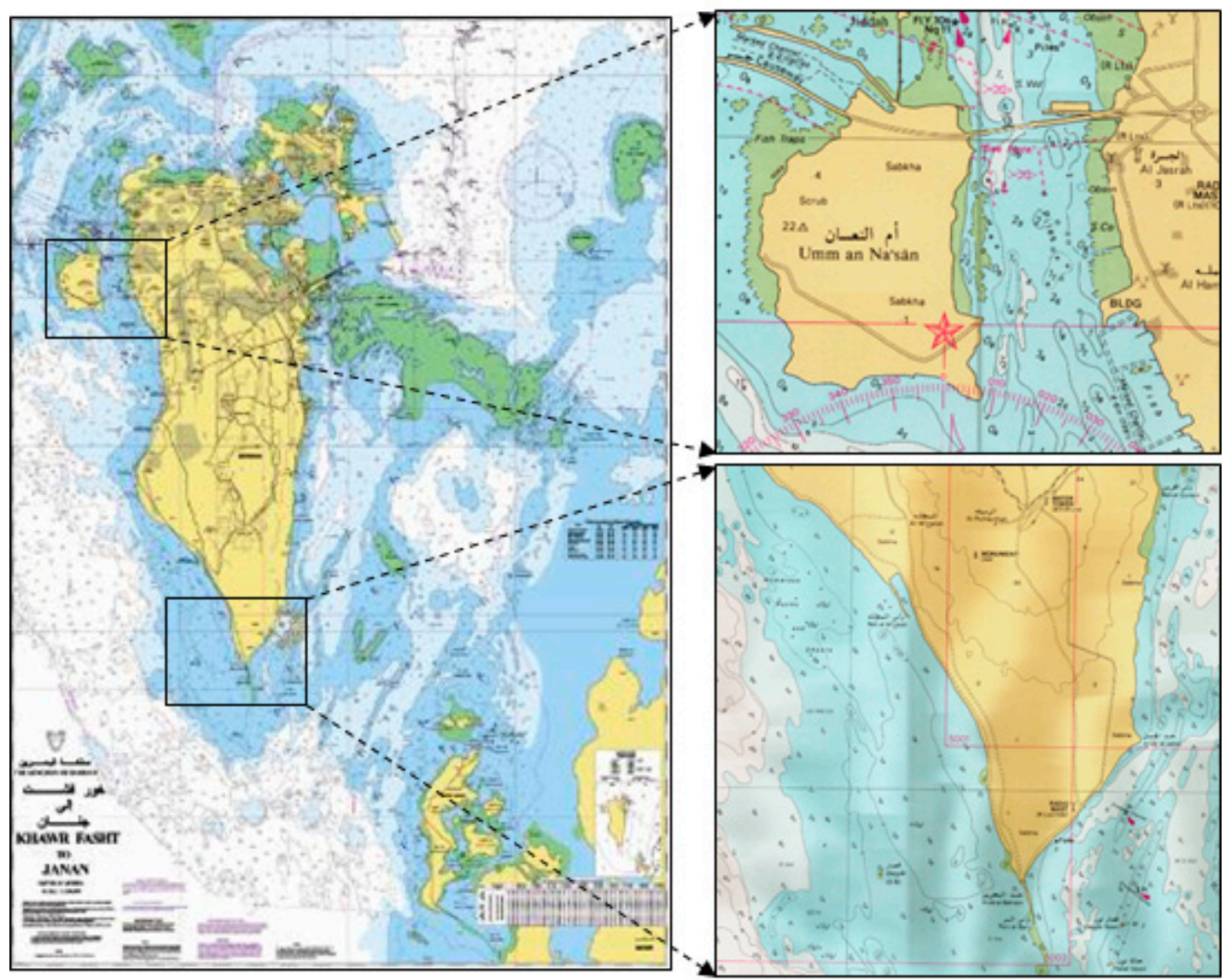

Figure 5. Bathymetric depth map $(1: 100,000)$ with zooms on two areas.

\section{Results}

Ordinary and simple kriging were both tested considering several mathematical models. Based on the cross-validation statistical analysis between the MBES-CARIS measured values (observations) introduced into the interpolation process and their estimated values (prediction) introduced by both kriging methods, simple kriging (SK) provides the best prediction results. During the SK implementation, the semi-variogram was adjusted to model the spatial autocorrelation between the measured depth samples considering exponential model and assuming a multiplicative skewing distribution. The interpolation procedure was carried out considering the 10,227 node-grid points that cover the Bahrain national water boundary, using eight (8) neighbour nodes, the number of lags was fixed at 12 and the lag size was 0.086 . Figure 6 shows the derived Bahrain bathymetry map by applying the SK, and superimposing the contours lines with $4 \mathrm{~m}$ equidistance that were extracted using 3D analyst module in ArcGIS. The output pixel size was fixed to a 30 by $30 \mathrm{~m}$, and the depth range varied between -0.5 and $-73 \mathrm{~m}$ below MSL. The areas in the southwest near Saudi Arabia and in the north near the Iranian water border show the higher depth compared to littoral. Shallow coastal 
areas rarely exceed a depth of $-15 \mathrm{~m}$. The main island of Bahrain is surrounded by areas where depth does not exceed $-10 \mathrm{~m}$. Other areas named "Fashts" that are very shallow seabed's (class with purple in Figures 6 and 7) lying in the intertidal zone, are mostly exposed during low tides and submerged during high tides. The average depth of these areas is around $-4 \mathrm{~m}$ and the depth of the surrounding "Fashts" areas reaches up to $-10 \mathrm{~m}$ below MSL. Figure 7 shows the 3D of the derived bathymetric map integrated with SRTM (Shuttle Radar Topographic Mission) land digital elevation model for topographic land representation.

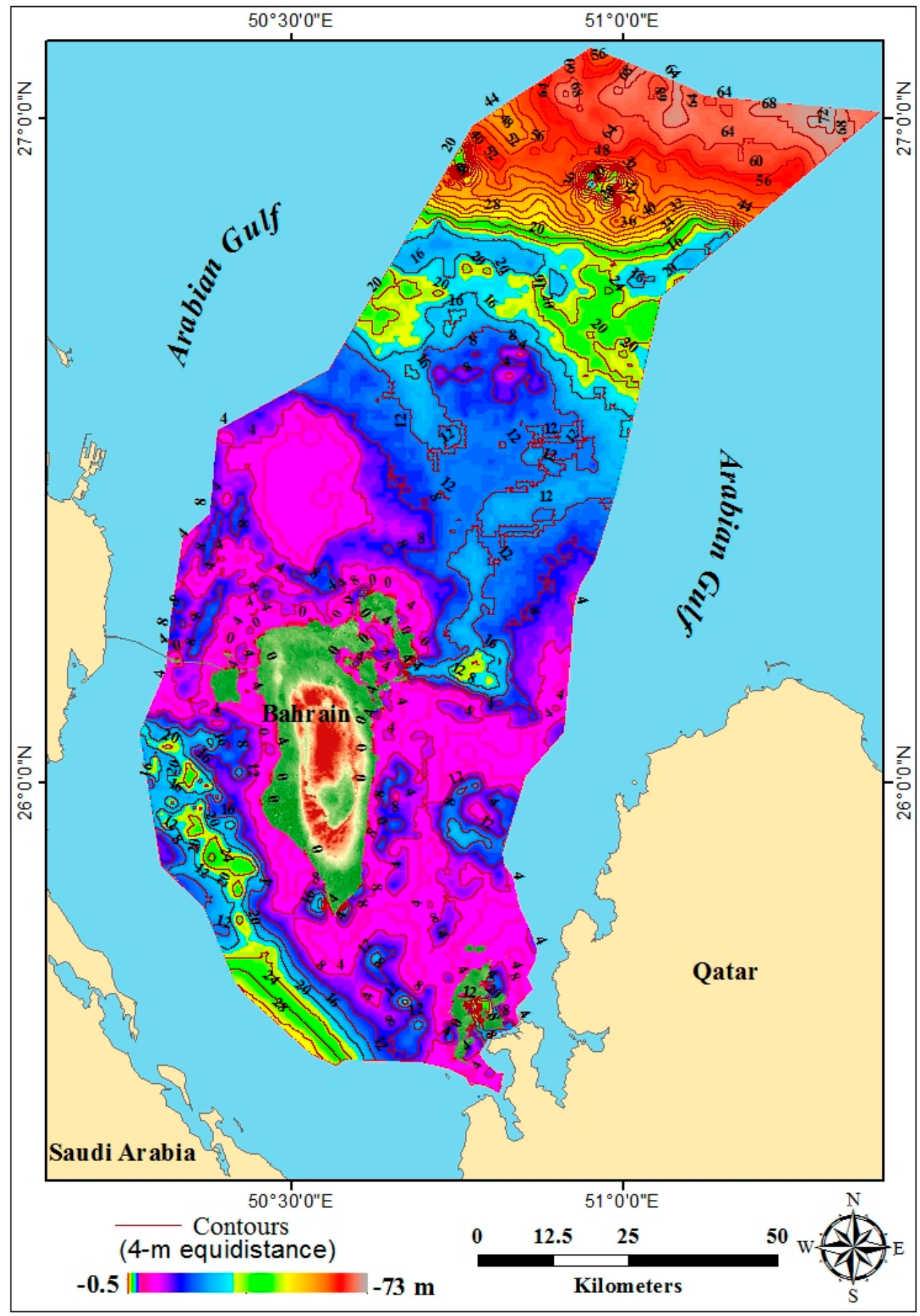

Figure 6. Bathymetric map derived using simple kriging and contours lines with $4 \mathrm{~m}$ equidistance. 


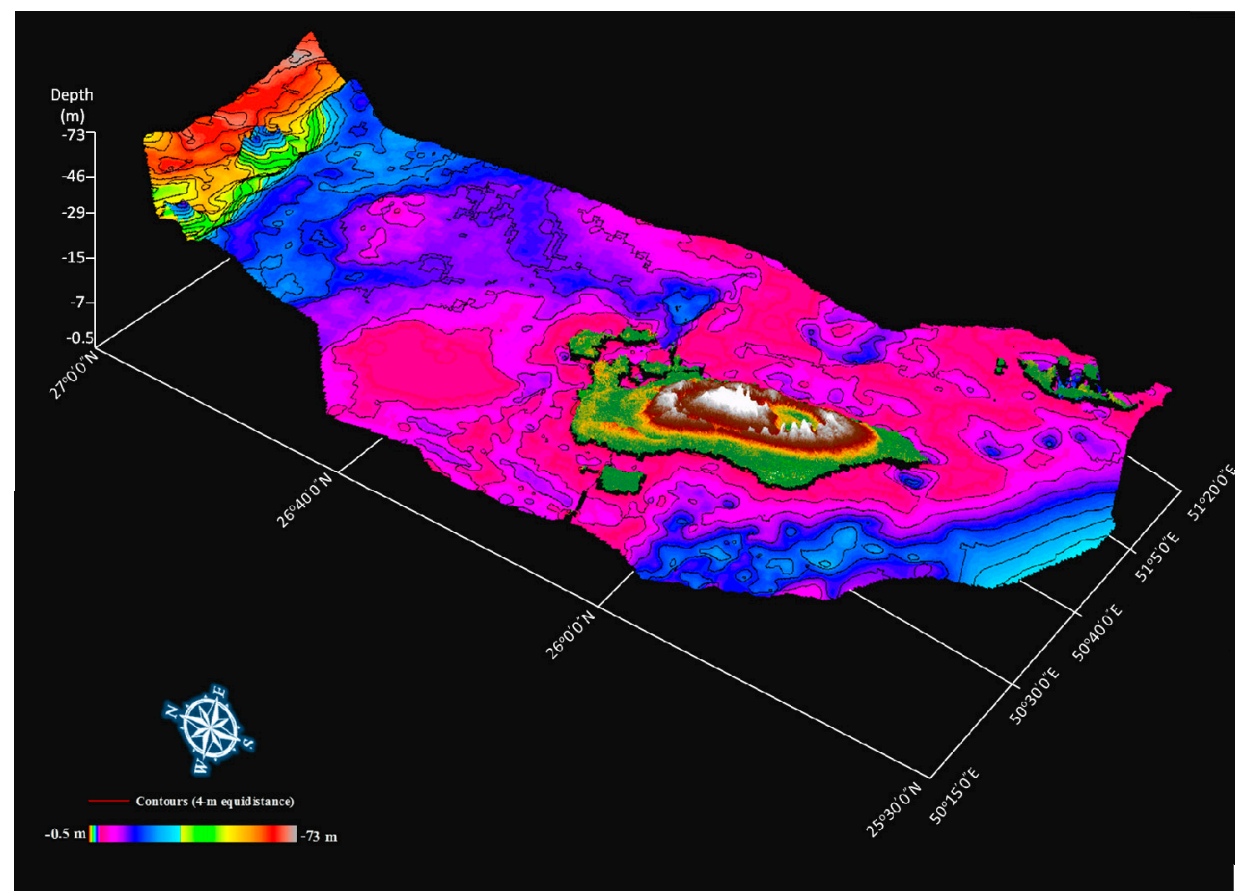

Figure 7. 3D of the derived bathymetric map integrated with SRTM land digital elevation model.

\subsection{Validation}

In the framework of this study, we conducted the validation procedure in two different steps. First, the cross-validation process between the measured depths with MBES-CARIS and the predicted depth for the same points using SK. This step is so important and helpful for spatial prediction to assess how well the estimation of unknown point's works (i.e., calculate the prediction errors and eliminate undesirable points). Second, is the validation by reference to the real water depths, which was performed using a medium scale $(1: 100,000)$ nautical map established in 1997 by British navy in cooperation with the Kingdom of Bahrain, Department of Hydrographic Services-Ministry of Environment (Figure 5). This map was established in accordance with the IHO standards with the accuracy of $\pm 0.30 \mathrm{~m}$ and $\pm 1.00 \mathrm{~m}$, respectively, for depths between -0 and $-30 \mathrm{~m}$ and depths between -30 and $-100 \mathrm{~m}[59]$.

Figure 8 illustrate the cross-validation method and it shows that the correlation between these two variables (measured vs predicted depth) is excellent $\left(R^{2}=0.99\right)$. However, we observed a few points (in green and red) distant from the other observations with little deviation from the 1:1 line. These green and red points ( 26 in total) represent some nodes with a depth between -25 to $-34 \mathrm{~m}$ and -35 to $-50 \mathrm{~m}$, respectively, and this relative deviation can be explained by the drastic change (increase or decrease) in the depths of the neighboring nodes used in the process of predicting these points. Nevertheless, these points were localized and eliminated before the final interpolation process [60]. The elimination of these 26 points that are biased did not have any impact on the interpolation results when we processed all the remaining points (i.e., 10,201 points) using simple kriging At this preliminary stage, as mentioned before, three types of errors were measured and evaluated in this cross-validation procedure. The MSE, which must be near zero for the best fit, had a value of 0.004 reflecting the appropriate fitting of the modeled semi-variogram (prediction errors are unbiased). The RMSE indicates how closely the model predicts the measured values, the smaller this error the better the prediction. The achieved value for this error is $0.94 \mathrm{~m}$; Curtarelli et al. [53] and USGS [30] obtained similar results, respectively, 0.92 and $0.90 \mathrm{~m}$. Finally, the RMSSE should be close to one if the prediction standard errors are valid. If it is greater or less than one, respectively, this means an underestimation or an overestimation of the variables under prediction. The calculated value 
for this error is 0.91 (very close to one), which means that the standard error prediction is valid, and the depth values are substantially overestimated by the SK algorithm. Indeed, the scatter plot presented in Figure 8 corroborates these error results. In addition, it also reveals that many other points are relatively underestimated. However, in general, this cross-validation reflects the best fit of the semi-variogram model after several tests, and the statistical errors analysis provides very satisfactory results. Consequently, the MBES-CARIS dataset were processed using SK to retrieve the final bathymetric map (Figure 6).

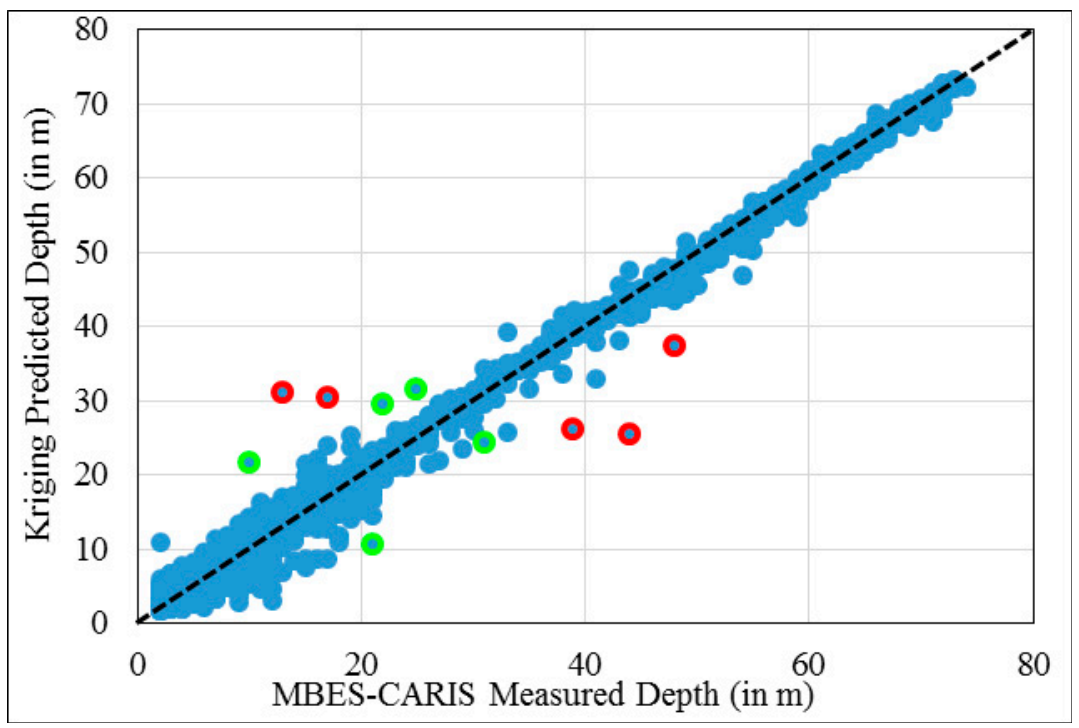

Figure 8. Cross-validation procedure between the measured depths with MBES-CARIS and the predicted depths for the same points using sample kriging. 0 Points with deviation from the 1:1 line.

Furthermore, for the derived bathymetric map validation by reference to the real water depths, the medium scale $(1: 100,000)$ nautical map was scanned and geo-referenced using first order polynomial functions and 10 ground control points (GCPs), assuring a planimetric correction error less than $0.5 \mathrm{~m}$. it was then overlaid on the generated MBES-CARIS raster bathymetric map (Figure 6) in GIS for homologous depth points' identification and selection. Shallow water between $-30 \mathrm{~m}$ and $-0.5 \mathrm{~m}$ depth over the Bahrain national water boundary was considered and 1200 validation points representing different water depths $(-0.5 \mathrm{~m} \leq$ depth $\leq-30 \mathrm{~m})$ were selected randomly and extracted for statistical analysis and validation purposes: 400 points were selected in water areas with depth $\geq-10 \mathrm{~m}$ and 800 point in areas with depth $<-10 \mathrm{~m}$.

Figure 9a illustrates the relationship between bathymetric depths from the nautical map (observed values) and predicted values from MBES-CARIS considering all validation points (1200) using linear regression $(p<0.05)$. We observe that the two considered variables correlate very significantly $\left(R^{2}\right.$ of $0.95)$ with a good index of agreement $(\mathrm{D}=0.82)$ but generate a relatively large RMSE $(1.34 \mathrm{~m})$. In fact, this RMSE is significantly larger than the accuracy $( \pm 0.30 \mathrm{~m})$ of the nautical map used for validation. The scatter plot presented in Figure 9a reveals that the fitted line (in red) through the scattered depths points do not fit the 1:1 theoretical line (black dashed line) perfectly. Depending on the water depths, sometimes the MBES-CARIS' observed values are overestimated and other times are underestimated, especially for depths between -30 and $-10 \mathrm{~m}$. Indeed, when we select and isolate only this depth class $(-10 \mathrm{~m} \leq$ depth $\leq-30 \mathrm{~m})$ represented by 800 validation points, as illustrated by the scatter plot presented in Figure 9b, the coefficient of correlation and index of agreement decrease $\left(R^{2}=0.79\right.$, and $\mathrm{D}=0.52)$ and the RMSE increases $(1.92 \mathrm{~m})$. This RMSE is higher with $1.52 \mathrm{~m}$ than the accuracy of the validation map. These results are expressed and reflected by the fitted regression line (in red) through the scattered depth points, which does not fit perfectly with the 1:1 theoretical line. Indeed, 
we see that the cloud of points do not tighten around the 1:1 line, the majority of validation points are overestimated and only a limited number of points are underestimated. This statement corroborates the cross-validation results discussed before, although we are using different and independent data (nautical map).

Furthermore, when we consider exclusively shallow water validation points $(\sim 400)$ with depths between -0.5 and $-10 \mathrm{~m}$, the scatter plot, as presented in Figure $9 \mathrm{c}$, reveals a good linear relationship concerning the two variables and shows a strong correlation $\left(R^{2}=0.97\right)$, a good agreement $(D=0.84)$ and a low RMSE $(0.51 \mathrm{~m})$. Moreover, the fitted line through the scatter depths points (given in red) coincide perfectly with the 1:1 theoretical line (black dashed line). According to the literature, the predicted nodes uncertainty on the acquired data with MBES and processed with CARIS-HIPS ranges from $0.31 \mathrm{~m}$ to $0.60 \mathrm{~m}$ in shallow areas $[18,28]$. However, although the errors propagation in the preprocessing and processing chain, from the raw data acquisition to the results validation, the obtained RMSE in this study for shallow water is within the norm of tolerance $(0.51 \mathrm{~m})$. As well as it is nearby to the validation map accuracy $( \pm 0.30 \mathrm{~m})$. Consequently, it can be concluded that the released-free MBES-CARIS data are more appropriate for shallow water bathymetric mapping. It is possible also that we obtained this good accuracy because the sallow regions in the nautical map were mapped accurately than the deeper regions.

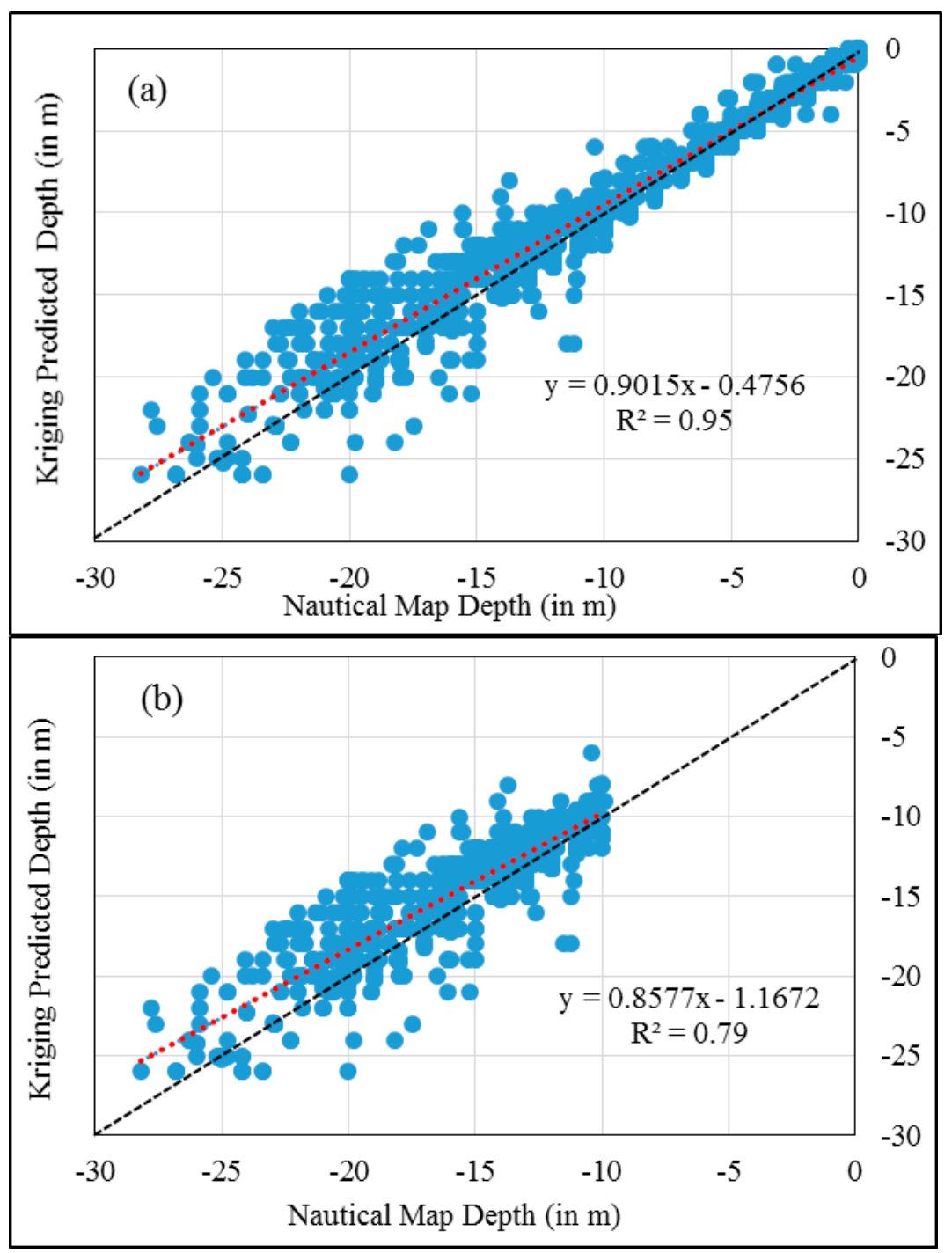

Figure 9. Cont. 


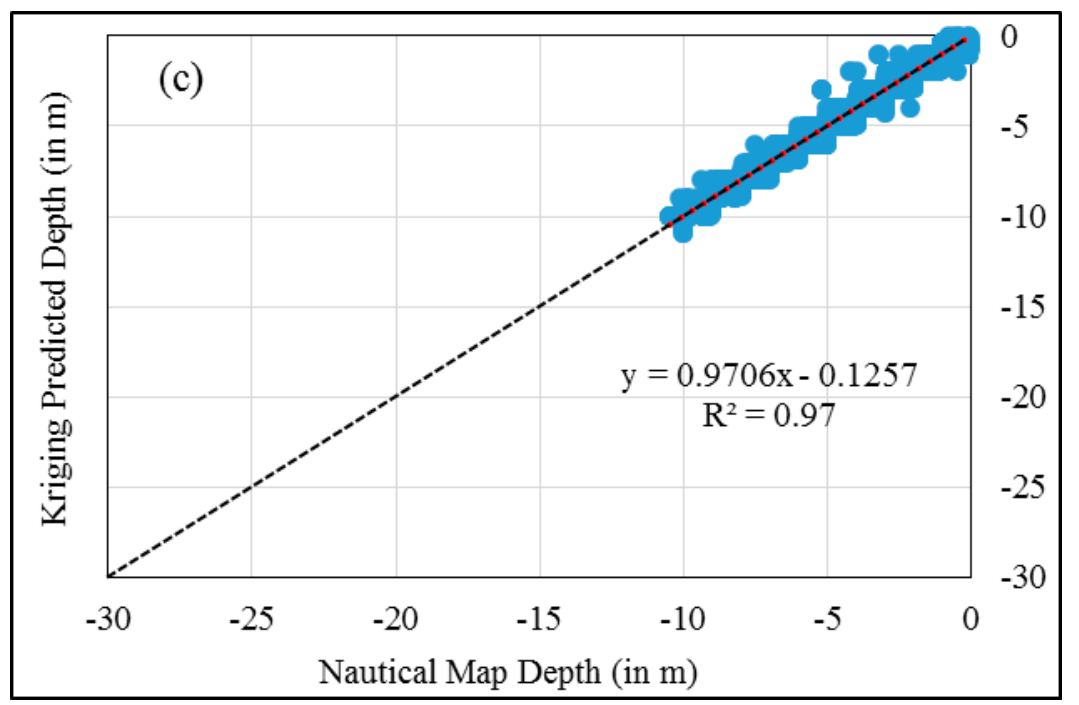

Figure 9. Relationship between bathymetric depths from nautical map (observed values) and predicted values from SK based on the measured MBES-CARIS. Depths between -30 and $0 \mathrm{~m}(\mathbf{a})$, depths between -30 and $-10 \mathrm{~m}(\mathbf{b})$, and depths between -10 and $0 \mathrm{~m}(\mathbf{c})$.

\subsection{Discussion}

Bathymetric information is very important for oceanographic management decisions, especially in the Kingdom of Bahrain where oil exploration operations are very active and many artificial small islands are under construction while others are under planning. Consequently, water depth information must be updated frequently. However, high quality bathymetric surface estimation is not an easy task because choosing the best mapping method is critical and depends on the investment and the required accuracy. There is no doubt that conventional methods are very accurate but at the same time very expensive and time-consuming for a very limited area. The proposed and available optical remote sensing methods are promising but unfortunately are very limited, and they have not arrived to the operational stage, especially for monitoring the change of the seafloor with acceptable accuracy. Nevertheless, the MBES has several advantages over these available alternatives [22] and provides the best way to determine the bathymetric information for large regions of the seabed [17]. Currently, the generated bathymetric attributed node-grid points using MBES were made available for users around the world in the GEBCO digital atlas database [39]. As we discussed before, in the literature the MBES-CARIS products were widely validated statically focussing on computer-assisted algorithms of estimating plausible depths from MBES raw data. Unluckily, the used algorithms are more complex and are based on several assumptions, as well as always assessed and validated only on a small subset of data [18,22-27]. In this research, we validated for the first time the free-released MBES-CARIS depth-surface data performance and its robustness for bathymetric mapping of shallow water at the regional scale. Certainly, the obtained results of this study can provide important information to policy and decision makers to get a sense of accuracy of these released data to predict ocean water depths, especially in the shallow areas.

Firstly, the cross-validation procedure results show that the MBES-CARIS data uncertainties have different degrees of impact according to the water depths. However, the prediction of only some node-points in areas with the depths between -20 and $-50 \mathrm{~m}$ exhibit significant errors, whereas in general cross-validation reflects the best fit of the semi-variogram model and the achieved statistical errors provide very satisfactory results (MSE $=0.004)$. Indeed, the accomplished RMSE $(0.94 \mathrm{~m})$ indicates how closely the model predicts the measured values. This error value is in agreement with the Curtarelli et al. [53] and USGS [30] results which measured, respectively, $0.92 \mathrm{~m}$ and $0.90 \mathrm{~m}$. 
Moreover, these findings corroborate other scientists' results [18], who studied the propagation of several sources of uncertainty in the MBES data preprocessing.

Secondly, the absolute validation by reference to the nautical map (that we assume representing the true depth of water) has shown that as we move away from the shallow areas the RMSE become more significant. Indeed, for the relatively deeper areas, the obtained RMSE reflects a lack of accuracy because probably the nautical map used for validation was not established with a good accuracy in the relatively deeper regions. Most likely the MBSE did not cover the bottom in several areas of deeper pockmarks because of the rapid change in depth. Steep slopes and rough seafloor probably affect the acquired raw data. The interpolation of missed areas' values between MBES acquisition data points may not reflect the true depths of these areas. The errors definitely vary according to the complexity of the marine morphology (curvature and rugosity) and relief (slope and orientation), MBES components (sensor quality and calibration, signal to noise ratio, gyroscope for attitude errors, GPS, etc.), sound speed, tides, and draft as discussed with several other scientists in the literature [27,61,62]. Moreover, other main artefacts can be caused by the combination of the different datasets acquired with multiple instruments from multiple surveys and are probably processed differently with several versions of CARIS-HIPS $[17,63,64]$. However, as this study illustrated, despite all these problems and error sources discussed above, the realised MBES-CARIS data are able to map properly the shallow water with satisfactory RMSE.

\section{Conclusions}

This research focuses on the validation of the released MBES-CARI dataset performance and robustness for bathymetric mapping of shallow water at the regional scale, covering the Kingdom of Bahrain national water boundary (Arabian Gulf). The data were imported, converted and interpolated using SK in a GIS environment. To assess how well the SK approximation works, the cross-validation process showed that the modeled semi-variogram was adjusted appropriately, assuring satisfactory results (MSE of 0.004; RMSE of $0.94 \mathrm{~m}$, and RMSSE of 0.91). For validation purposes by reference to the truth of the water depths, 1200 bathymetric points representing different water depths $(-0.5 \mathrm{~m} \leq$ depth $\leq-30 \mathrm{~m}$ ) across the Bahrain national water boundary were selected randomly and extracted from a medium scale $(1: 100,000)$ nautical map were used. We obtained relatively different results depending on the depth zones. In fact, when we consider all the depths (1200 validation points), the statistical analysis using linear regression $(p<0.05)$ provides a good $\mathrm{R}^{2}(0.95)$ and $\mathrm{D}(0.82)$, as well as an RMSE of $1.34 \mathrm{~m}$. However, when we consider only the zones with depths less than $-10 \mathrm{~m}$ ( 800) with), the $\mathrm{R}^{2}$ and D decreased to 0.79 and 0.52 , respectively, and the RMSE increased to $1.92 \mathrm{~m}$. Otherwise, when we consider exclusively shallow water with a depth higher than $-10 \mathrm{~m}(\sim 400)$ the results showed a very significant $R^{2}(0.97)$, a good D $(0.84)$ and a low RMSE $(0.51 \mathrm{~m})$. Certainly, the released-free MBES-CARIS data are more appropriate for shallow water bathymetric mapping. However, for the relatively deeper areas the obtained results are relatively less accurate because the nautical map used for validation probably was not established with a good accuracy in the relatively deeper regions. Most likely the MBSE did not cover the bottoms in several deeper pockmarks because of rapid change in depth. The steep slopes and the rough seafloor probably affect the acquired raw data. Moreover, the interpolation of the missed areas values between MBSE acquisition swaths-lines (ship-tracked sounding data) may not reflect the true depths of these areas. Other main artefacts can be caused by the combination of the different datasets acquired with multiple instruments from multiple surveys and probably processed differently with several versions of CARIS-HIPS. However, globally the results of the MBES-CARIS data are very appropriate for bathymetric mapping of shallow water areas. 
Acknowledgments: The authors would like to thank the Arabian Gulf University for their financial support. Our gratitude to Charles de Jongh (CARIS EMEA, The Netherlands) for MBES-CARIS datasets. Finally, we express gratitude to the anonymous reviewers for their constructive comments.

Author Contributions: Abderrazak Bannari performed the paper concept, data analysis and wrote the paper. Ghadeer Kadhem participated in the processing steps and the figures preparation.

Conflicts of Interest: The authors declare no conflict of interest.

\section{References}

1. Costanza, R.; D’Arge, R.; De-Groot, R.; Farber, S.; Grasso, M.; Hannon, B.; Limburg, K.; Naeem, S.; O'Neill, R.V.; Paruelo, J.; et al. The value of the world's ecosystem services and natural capital. Nature 1997, 387, 253-260. [CrossRef]

2. Tokoro, T.; Hosokawa, S.; Miyoshi, E.; Tada, K.; Watanabe, K.; Montani, S.; Kayanne, H.; Kuwae, T. Net uptake of atmospheric $\mathrm{CO}_{2}$ by coastal submerged aquatic vegetation. Glob. Chang. Biol. 2014, 20, 1873-1884. [CrossRef] [PubMed]

3. Burke, L.; Reytar, K.; Spalding, M.; Perry, A. Reefs at Risk Revisited; World Resources Institute: Washington, DC, USA, 2011; p. 230.

4. Ilori1, C.; Knudby, A. Deriving Water Depth; Bottom Features and Water Column Optical Properties Using Satellite Remote Sensing, 2015. Available online: http:/ / rose.geog.mcgill.ca/ski/webfm_send/409 (accessed on 18 March 2016).

5. Jagalingam, P.; Akshaya, B.J.; Hegde, A.V. Bathymetry mapping using Landsat 8 satellite imagery. Proced. Eng. 2015, 116, 560-566. [CrossRef]

6. Rainforest Research Center. Status of Coral Reefs of the World: 2008; Wilkinson, C., Ed.; Global Coral Reef Monitoring Network: Townsville, Australia, 2008; p. 296.

7. Hamylton, S.M.; Hedley, J.D.; Beaman, R.J. Derivation of high-resolution bathymetry from multispectral satellite imagery: A comparison of empirical and optimisation methods through geographical error analysis. Remote Sens. 2015, 7, 16257-16273. [CrossRef]

8. Lee, Z.; Carder, K.L.; Mobley, C.D.; Steward, R.G.; Patch, J.S. Hyperspectral remote sensing for shallow waters: 2. Deriving bottom depths and water properties by optimization. Appl. Opt. 1999, 38, 3831-3843. [CrossRef] [PubMed]

9. Jawak, S.D.; Vadlamani, S.S.; Luis, A.J. A synoptic review on deriving bathymetry information using remote sensing technologies: Models, methods and comparisons. Adv. Remote Sens. 2015, 4, 147-162. [CrossRef]

10. Collin, A.; Archambault, P.; Long, B. Mapping the Shallow Water Seabed Habitat with the SHOALS. IEEE Trans. Geosci. Remote Sens. 2008, 46, 2947-2955. [CrossRef]

11. Hughes-Clarke, J.M. Shallow-water imaging multibeam sonars: A new tool for investigating sea floor processes in the coastal zone and on the continental shelf. Mar. Geophys. Res. 1996, 18, 607-629. [CrossRef]

12. Costa, T.A. Comparative evaluation of airborne LiDAR and ship-based multibeam sonar bathymetry and intensity for mapping coral reef ecosystems. Remote Sens. Environ. 2009, 113, 1082-1100. [CrossRef]

13. Schimel, A.C.G.; Healy, T.R.; Johnson, D.; Immenga, D. Quantitative experimental comparison of single-beam, sidescan and multibeam benthic habitat maps. ICES J. Mar. Sci. 2010, 67, 1766-1779. [CrossRef]

14. Schimel, A.C.G.; Healy, T.R.; McComb, P.; Immenga, D. Comparison of a self-processed EM3000 multibeam echosounder dataset with a QTC View habitat mapping and a side-scan sonar imagey, Tamaki Strait, New Zealand. J. Coast. Res. 2010, 26, 714-725. [CrossRef]

15. Smith, T.A.; McConnaughey, R.A. The Applicability of SONARs for Habitat Mapping: A Bibliography. U.S.; NMFS-AFSC-317; Department of Commerce, NOAA Tech.: Silver Spring, MD, USA, 2016.

16. Cleveland, G.S. A Comparative Analysis of Shallow Water Mapping Tools. Master's Thesis, Department of Geography and Geo-Information Science, George Mason University, Fairfax, VA, USA, 2015.

17. Calder, B.R.; Mayer, L.A. Automatic processing of high-rate; high-density multibeam echosounder data. Geochem. Geophys. Geosyst. 2003. [CrossRef]

18. Lucieer, V.; Huang, Z.; Siwabessy, J. Analysing Uncertainty in Multi-beam Bathymetric Data and the impact on derived seafloor attributes. Mar. Geod. 2016, 39, 32-52. [CrossRef] 
19. Calder, B.; Wells, D. CUBE User's Manual, Version 1.13; Center for Coastal and Ocean Mapping and NOAA/UNH Joint Hydrographic Center, University of New Hampshire: Durham, NH, USA, 2007.

20. CARIS Trust the Most Comprehensive Hydrographic and Sonar Data Processing System, 2015. Available online: http:/ /www.caris.com/products/hips-sips/ (accessed on 10 December 2016).

21. Wyllie, K.; Weber, T.C.; Armstrong, A. Using Multibeam Echosounder for hydrographic surveying in the water column: estimating wreck least depths. In Proceedings of the US Hydrographic Conference, National Harbor, MD, USA, 16-19 March 2015.

22. Calder, B. Distribution-free, Variable Resolution Depth Estimation with Composite Uncertainty; Center for Coastal and Ocean Mapping. Available online: http://scholars.unh.edu/ccom/859 (accessed on 5 January 2017).

23. Calder, B.; Mayer, L.A. Robust Automatic Multi-beam Bathymetric. Processing of the U.S. Hydrographic Conference, Norfolk (VA; USA). Available online: http://scholars.unh.edu/ccom/216 (accessed on 5 January 2017).

24. Hare, R. Error Budget Analysis for the Naval Hydrographic Office (NAVOCEANO) Hydrographic Survey Systems; Technical Report; University Southern Mississippi: Hattiesburg, MS, USA, 2001.

25. Hare, R.; Godin, A.; Mayer, L.A. Accuracy Estimation of Canadian Swath (Multi-Beam) and Sweep (Multi-Transducer) Sounding Systems; Technical Report; Canadian Hydrographic Service: Ottawa, ON, Canada, 1995.

26. Beaudoin, J.; Calder, B.; Hiebert, J.; Imahori, G. Estimation of sounding uncertainty from measurements of water mass variability. Int. Hydrogr. Rev. 2009, 2, 20-38.

27. Dolan, M.F.J.; Lucieer, V.L. Variation and uncertainty in bathymetric slope calculations using geographic information systems. Mar. Geod. 2014, 37, 187-219. [CrossRef]

28. Smith, S.M.; Alexander, L.; Armstrong, A.A. The navigation surface: A new database approach to creating multiple products from high-density surveys. Int. Hydrogr. Rev. 2002, 3, 12-26.

29. Fonseca, L.; Mayer, L. Remote estimation of surficial seafloor properties through the application of Angular Range Analysis to multi-beam sonar data. Mar. Geophys. Res. 2007, 28, 119-126. [CrossRef]

30. USGS Archive of Side-scan Sonar and Swath Bathymetry Data Collected During USGS Cruise 13CCT04 Offshore of Petit Bois Island, Gulf Islands National Seashore, Mississippi, August 2014. Available online: https://pubs.usgs.gov/ds/0917/ds917_data_processing.html (accessed on 25 September 2016).

31. BSH. Nautical Chart; INT-905; Northern Weddell Sea. Available online: http://apps3.awi.de/eBathy/ int905/int905.html (accessed on 5 January 2017).

32. Nistad, J.-G.; Lavoie, F.; Cove, K. An Evaluation of CARIS Bathy DataBASE as a Bathymetric Data Management Solution for CHS Quebec. Paper 5-1. In Proceedings of the Canadian Hydrographic Conference and National Surveyors Conference, Victoria, BC, Canada, 26-29 March 2008.

33. Cove, K.; Lavoie, F. Addressing the Need for a Bathymetric Data Management System. In Proceedings of the US Hydro 2007 Conference, Norfolk, VA, USA, 14-17 May 2007.

34. Canadian Hydrographic Service. CUBE Bathymetric Data Processing and Analysis, 1st ed.; Canadian Hydrographic Service, Fisheries and Oceans Canada: Ottawa, ON, Canada, 2012.

35. Vásquez, M.E. Tuning the CARIS Implementation of CUBE for Patagonian Waters. Master's Thesis, Department of Geodesy and Geomatics Engineering, University of New Brunswick, Fredericton, NB, Canada, 2007.

36. Schimel, A.C.G.; Ierodiaconou, D.; Hulands, L.; Kennedy, D.M. Accounting for uncertainty in volumes of seabed change measured with repeat multibeam sonar surveys. Cont. Shelf Res. 2015, 111, 52-68. [CrossRef]

37. IHO. International Hydrographic Organization. IHO Standards for Hydrographic Surveys, 5th ed.; Special Publication No. 44; International Hydrographic Bureau: Monaco, 2008; p. 28. Available online: https: //www.iho.int/iho_pubs/standard/S-44_5E.pdf (accessed on 5 January 2017).

38. Fellinger, C. CSAR: A New Approach for Handling High Volume Bathymetry. In Proceedings of the International Federation of Surveyors Congress, Sydney, Australia, 11-16 April 2010.

39. General Bathymetric Chart of the Oceans (GEBCO). The IHO-IOC GEBCO Cook Book. Available online: http:/ / www.gebco.net/data_and_products/gebco_cook_book/ (accessed on 15 January 2017).

40. Law, M.; Collins, A. Getting to Know ArcGIS. Available online: http:/ / esripress.esri.com/bookresources/ index.cfm? event=catalog.book\&id=16 (accessed on 15 January 2017). 
41. Central Informatics Organization (CIO). Kingdom of Bahrain, Statistical Abstract, 2015. Available online: http://www.cio.gov.bh/cio_eng/default.aspx (accessed on 21 January 2016).

42. Environmental Affairs. The Kingdom of Bahrain; Ministry of State; Municipalities Affairs and Environmental Affairs: National Report to the World Summit on Sustainable Development. Available online: http://www.unep.org/dewa/westasia/data/Knowledge_Bases/Bahrain/Reports/bahrain_natl_ assess1207.pdf (accessed on 7 January 2017).

43. Ministry of Works and Housing, Kingdom of Bahrain. Analysis of Data Suitability of the Site, Environmental Conditions + Existing Networks; Ministry of Works and Housing, Kingdom of Bahrain: Manama, Bahrain, 2002.

44. Choudhury, P.R. Marine Habitat Mapping in a Shallow Sea Area of Bahrain Using Remote Sensing and Field Survey Data. Available online: http://www.watercolumncorrection.com/documents/P50.pdf (accessed on 5 January 2017).

45. Abdulqader, E.; Sadiq, A.; Al Noami, A. Fishermen and Fish Catch in the Kingdom of Bahrain from a Socio-Economic Perspective; Bahrain center for Studies and Research: Manama, Bahrain, 2004.

46. Zainal, A.; Al-Zayani, A.; Abdulqader, E.; Burshaid, F.; Roy, P. Marine Environmental Geographic Information System (MARGIS-II); Bahrain Center for Studies and Research: Manama, Bahrain, 2006.

47. Li, J.; Heap, A.D. A Review of Spatial Interpolation Methods for Environmental Scientists; Australian Government, Geoscience Australia: Symonston, Australia, 2008.

48. Isaaks, E.H.; Srivastava, R.M. Applied Geostatistics; Oxford University Press: New York, NY, USA, 1989.

49. Weng, Q. Comparative assessment of spatial interpolation accuracy of elevation data. In Proceedings of the 1998 ACSM Annual Convention and Exhibition, Baltimore, MD, USA, 1-5 March 1998.

50. Burrough, P.A.; McDonnell, R.A. Principles of Geographical Information Systems; Oxford University Press: New York, NY, USA, 1998; pp. 333-335.

51. Zimmerman, D.; Pavlik, C.; Ruggles, A.; Armstrong, M. An experimental comparison of ordinary and universal Kriging and inverse distance weighting. Math. Geol. 1999, 31, 375-390. [CrossRef]

52. Arun, P.V. A comparative analysis of different DEM interpolation methods. Egypt. J. Remote Sens. Space Sci. 2013, 16, 133-139. [CrossRef]

53. Curtarelli, M.; Leão, J.; Ogashawara, I.; Lorenzzetti, J.; Stech, J. Assessment of spatial interpolation methods to map the bathymetry of an Amazonian hydroelectric reservoir to aid in decision making for water management. ISPRS Int. J. Geo-Inf. 2015, 4, 220-235. [CrossRef]

54. Šiljeg, A.; Lozic, S.; Šiljeg, S. A comparison of interpolation methods on the basis of data obtained from a bathymetric survey of Lake Vrana, Croatia. Hydrol. Earth Syst. Sci. 2015, 19, 3653-3666. [CrossRef]

55. Bottelier, P.; Briese, C.; Hennis, N.; Lindenberg, R.; Pfeifer, N. Distinguishing Features from Outliers in Automatic Kriging-Based Filtering of MBES Data: A Comparative Study; Springer: Berlin, Germany, 2005; pp. 403-414.

56. Kielland, P.; Dagbert, M. Third generation electronic charts: what they provide users and how to produce them. In Proceedings of the Seventh International Offshore and Polar Engineering Conference, Honolulu, HI, USA, 25-30 May 1997.

57. Zhang, H.; Wang, Y. Kriging and Cross-Validation for Massive Spatial Data; Department of Statistics, Purdue University: Lafayette, IN, USA, 2009.

58. Willmott, C.J. Some comments on the evaluation of model performance. Bull. Am. Meteorol. Soc. 1982, 63, 1309-1313. [CrossRef]

59. Howlett, C. The IHO's New Standard for Hydrographic Surveys. Available online: http://www. hydroconferences.org/documents/hydroconferences/downloads/1/paper_12_-_chris_howlett.pdf (accessed on 6 April 2017).

60. Grubbs, F.E. Procedures for Detecting Outlying Observations in Samples. Available online: http://www. jstor.org/stable/1266761 (accessed on 5 January 2017).

61. Lundblad, E.R.; Wright, D.J.; Miller, J.; Larkin, E.M.; Rinehart, R.; Naar, D.F.; Donahue, B.T.; Anderson, S.M.; Battista, T. A benthic terrain classification scheme for American Samoa. Mar. Geod. 2006, 29, 98-111. [CrossRef]

62. Wilson, M.; O'Connell, B.; Brown, C.; Guinan, J.C.; Grehan, A.J. Multiscale terrain analysis of multi-beam bathymetry data for habitat mapping on the continental slope. Mar. Geod. 2007, 30, 3-35. [CrossRef] 
63. Lecours, V.; Dolan, M.F.J.; Micallef, A.; Dolan, V.L. A review of marine geomorphometry; the quantitative study of the seafloor. Hydrol. Earth Syst. Sci. 2016, 20, 3207-3244. [CrossRef]

64. Lecours, V.; Dolan, M.F.J.; Micallef, A.; Lucieer, V.L. Characterising the ocean frontier: A review of marine geomorphometry. Hydrol. Earth Syst. Sci. 2016. [CrossRef]

(c) 2017 by the authors. Licensee MDPI, Basel, Switzerland. This article is an open access article distributed under the terms and conditions of the Creative Commons Attribution (CC BY) license (http:/ / creativecommons.org/licenses/by/4.0/). 